\title{
DEVELOPMENT OF A FLOOD RISK ASSESSMENT MODEL FOR A BRAIDED RIVER SYSTEM
}

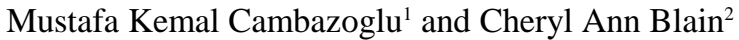

\begin{abstract}
The aim of this study is to construct a modeling system that will assist flood risk management strategies in a coastal plain braided river system. The model configuration consists of a hydrodynamic model (ADCIRC) of the river basin that receives tidal forcing at the open boundary and river discharge forcing at upstream flux boundary. An unstructured mesh model resolving the Pearl River channels at higher resolution from the coastline to approximately $75 \mathrm{~km}$ inland to upstream reaches of the river has been constructed. The modeling system produces water levels and currents throughout the Lower Pearl River Basin. Initial sensitivity analysis efforts on the channel model include consideration of low-flow, average-flow, and high-flow scenarios. Model results were found to be slightly sensitive to slope of river channels and bottom friction to control stability in predictions. The model results were shown to be highly sensitive to the bathymetry of the model that controls the discharge capacity of the narrow river channels and the channel model resulted in elevated currents and water levels under high flow conditions. A channel discharge capacity analysis was conducted and the results showed the need to construct a floodplain mesh around the channel model with more realistic bathymetry and topography so that the flooding scenarios could be modeled with wetting and drying capability of ADCIRC. An initial attempt to develop such a floodplain mesh has been made with preliminary results and more comprehensive validation of the developed floodplain modeling system will extend to reproducing events associated with the historical Hurricane Isaac that impacted the region in 2012. This modeling system will provide an important tool to decision makers that could be used in future flood risk management and mitigation efforts.
\end{abstract}

Keywords: Pearl River; unstructured grid; finite element modeling; ADCIRC; river dynamics

\section{INTRODUCTION}

The Lower Mississippi River Forecast Center (LMRFC) is one of 13 NOAA National Weather Service (NWS) centers in the United States that makes decisions on flood risk management control strategies and that is responsible for warning local authorities and emergency managers before and during flood events. LMRFC covers the watersheds that flow into the Gulf of Mexico on the Louisiana and Mississippi coastlines, including the Pearl River basin (Figure 1). Presently, the historic hydrographs used by NOAA-NWS LMRFC to predict flood conditions in the Lower Pearl River Basin, particularly south of Interstate-10, have been unreliable, and no numerical hydrodynamic model forecast capability currently exists. To address this capability gap, federal and local government partners came together with research partners to address needs and interests in regards to flood risk management and mitigation with an objective to develop a modeling system that simulates existing conditions in the Lower Pearl River Basin for water levels and currents. This model will serve as a tool for analyses of past major events as well as a capability for predicting future events that will enable improved warning and management strategies.

\section{STUDY AREA}

The study area focuses on the Lower Pearl River basin in southern Mississippi and southeastern Louisiana, covering approximately $75 \mathrm{~km}$ inland from the coastline. The Pearl River is examined starting just south of Bogalousa, LA where it splits into two distinct channels forming the East and West branches of the Pearl; both of which flow into Lake Borgne, continue into the Mississippi Sound and eventually flow into the Gulf of Mexico (Figure 1). The West Pearl river discharges into Lake Borgne and the Rigolets (the narrow passage connecting Lake Borgne to Lake Ponchartrain shown in Fig. 1(d)) in Louisiana while the East Pearl river forms the political boundary between the states of Louisiana and Mississippi and flows directly into the Mississippi Sound. Both channels have strong tidal influence especially during low river discharge conditions and regularly flood and drain the intertidal marshes near the river mouth (McKay and Blain, 2013).

\footnotetext{
${ }^{1}$ Division of Marine Science, School of Ocean Science and Technology, The University of Southern Mississippi, 1020 Balch Blvd., Stennis Space Center, City, MS, 39529, USA

${ }^{2}$ Oceanography Division, U.S. Naval Research Laboratory, Stennis Space Center, MS, 39529, USA
} 
Historically, the West Pearl had higher flows at the split (NASA, 2001), but, the East Pearl is much wider in its lowest reaches. In comparing LANDSAT imagery from 1986 to that from 2010, in-situ depth measurements taken by St. Tammany Parish in 2014-2015, and other anecdotal evidence suggest that flow on the West Pearl is diminishing, especially below Interstate-10 (I-10). Given these changes observed within the Lower Pearl River Basin and the lack of reliable forecast capability for flood risk management, the aim is to develop a numerical modeling system that will resolve details of the flow in this braided river system in order to be able to make realistic predictions towards flood risk assessment.

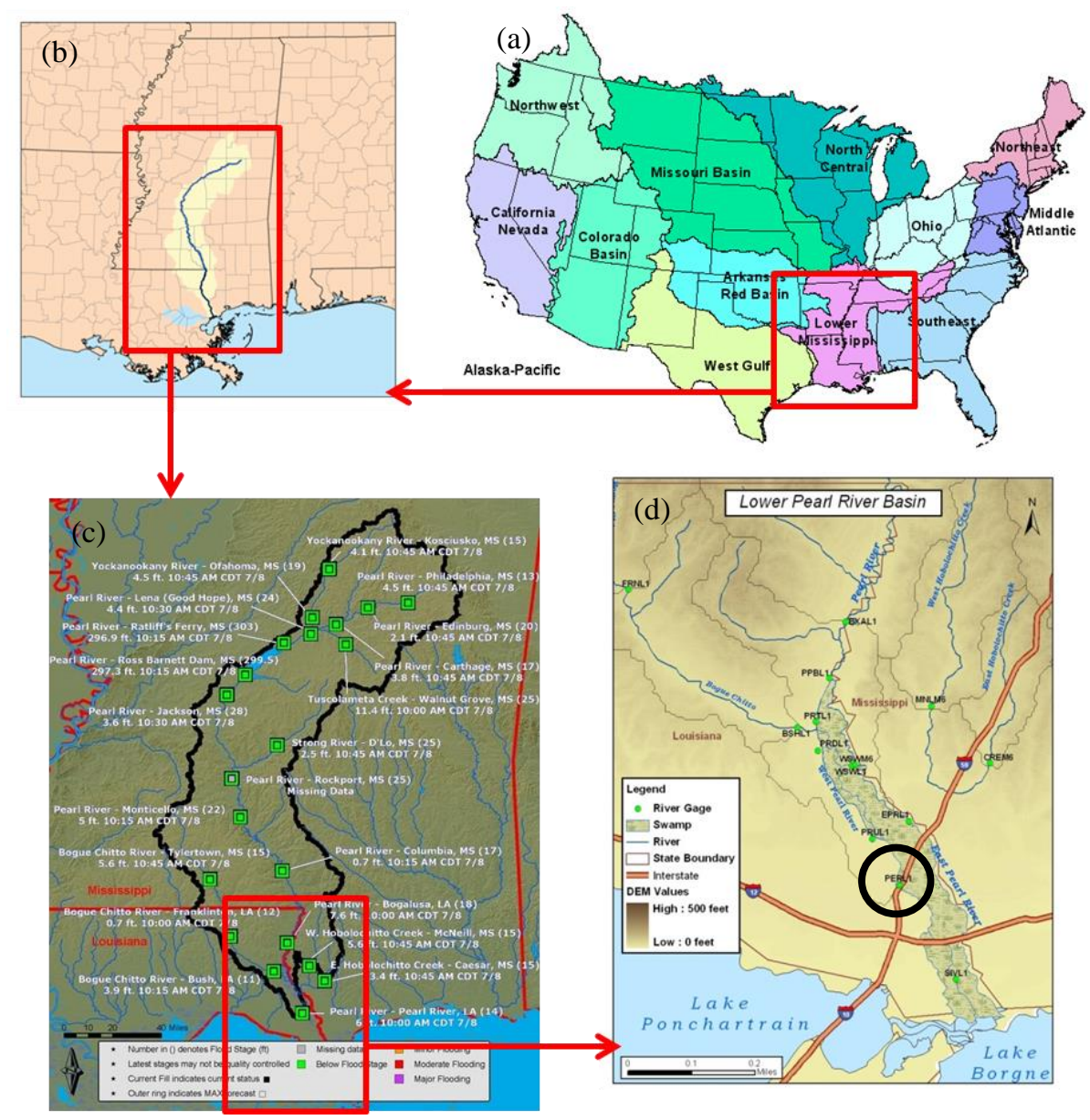

Figure 1 - (a) NOAA National Weather Forecast Center areas, (b) Lower Mississippi River Forecast Center (LMRFC) area, (c) Pearl River basin with LMRFC river gage locations, (d) Lower Pearl River basin with LMRFC river gages showing Pearl River at Pearl River station in black circle (PERL1).

\section{MODELING SYSTEM}

In this study, the Advanced Circulation Model (ADCIRC) was used as the hydrodynamic modeling system. ADCIRC uses the finite-element method to solve the depth-integrated shallow water wave equations (Luettich et al. 1992, Luettich and Westerink, 2004). ADCIRC has been extensively used for storm surge predictions in coastal areas, estuarine and coastal circulation and also recently for riverine modeling (e.g., Blain et al. 2012, Blain et al. 2009). The unstructured mesh of ADCIRC provides the high resolution needed to be able to resolve the complex and meandering narrow channels of the Pearl River especially in the Lower Pearl River Basin as well as the complex coastline in coastal Louisiana and Mississippi. The model, subject to tidal variations at the mouth and upstream discharge, produces water levels, i.e. elevation, and currents, i.e. river flow velocity. The tidal forcing is provided using information from six harmonic constituents extracted from the FES99 tidal database (Lefevre et al., 2002) and applied at the open water boundary in Lake Borgne in the eastern end of the Mississippi 
Sound. A river flux is prescribed at the far north upstream boundary. The bottom friction is captured by a nonlinear, quadratic formulation. The wetting and drying capability of ADCIRC will allow for channel overflow into the floodplain in future work.

\section{Development of a River Channel Model}

The unstructured mesh of ADCIRC is constructed using a pre-generated boundary coastline and bathymetric information (McKay and Blain, 2010). Due to lack of accurate field surveys that define all channel banks for the wide study area, aerial remote sensing imagery was used to identify the river channels in areas where no information is available (McKay and Blain, 2014). LA 1m resolution aerial IR Digital Orthoimagery quarter quadrangle (DOQQ) tiles from LSU LIDAR imagery Atlas were used as the data source to extract river edge and water locations (National Mapping Program, 1996). This data was processed to get river shoreline coordinates (Blain et al., 2013). At first water and land pixels of imagery were separated based on a hue selection criterion (Tanaka, 2006). This procedure was followed by the detection of water edges using a Laplace edge finding filter technique (Russ, 2002). The resulting mesh for the river channel network was also cross-checked to recently derived land/water mask from unmanned aerial system (UAS) imagery taken in December, 2014 by Mississippi State University (Moorhead, 2014). Figure 2 shows excellent agreement between sections of the meshed West, Mid, Middle and East Pearl river channels as compared to the land/water mask derived from UAS imagery.

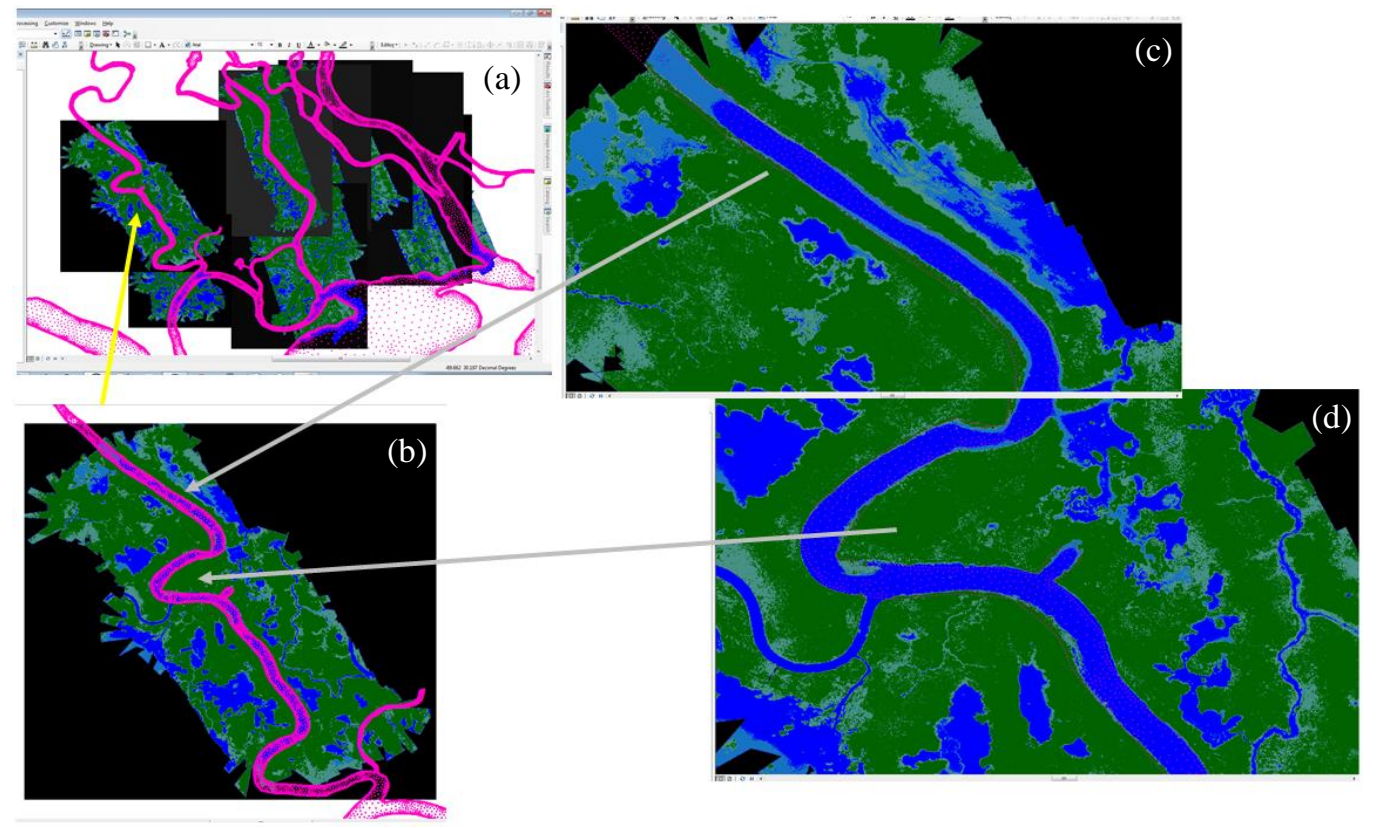

Figure 2 - (a)\&(b) West Pearl River channel mesh developed from earlier satellite-based remote sensing imagery compared to (c)\&(d) a recent (December 2014, Mississippi State University) land/water mask derived from UAS imagery of the West Pearl River and its surrounding floodplain in Louisiana.

The lack of bathymetry measurements in the West Pearl River precipitated the application of a synthetic bathymetry based on a cubic relationship between the channel width and depth (Equation 1):

$$
d=|x|^{1 / 3}
$$

in which $d$ is the depth of any given interior computational node in the model mesh and $x$ is the distance of the node to the closest bank. This method automatically resulted in deeper (shallower ) channels for wider (narrower) sections of the river. The generated depth values of the channels were later based on the topographic heights of the river edge/bank nodes which was provided from the topographic information used in an earlier unstructured mesh (SL16 mesh) with more than 5 million nodes and 9 million elements, developed for a larger study area covering southeastern United States and western North Atlantic Ocean used for previous Hurricane simulations (Dietrich, et al. 2011). 
The river channel mesh has $139 \mathrm{~K}$ nodes and $219 \mathrm{~K}$ elements with resolution as high as $4 \mathrm{~m}$ in the narrowest channels of the basin and as low as $250 \mathrm{~m}$ in open waters near the open boundary. Figure 3 shows the river channel mesh in perspective to four nearby NWS discharge stations at Bogalousa (BXAL1), Bogue Chitto (BSHL1), East Hobolochitto (MNLM6) and West Hobolochitto (CREM6). Depicted in the inset are the West, Mid-, Middle- and East Pearl river channels represented with high resolution in the constructed mesh. For the river channel mesh in Figure 3, applied discharge at the northern most boundary will be derived from conditions at Bogalousa, LA.

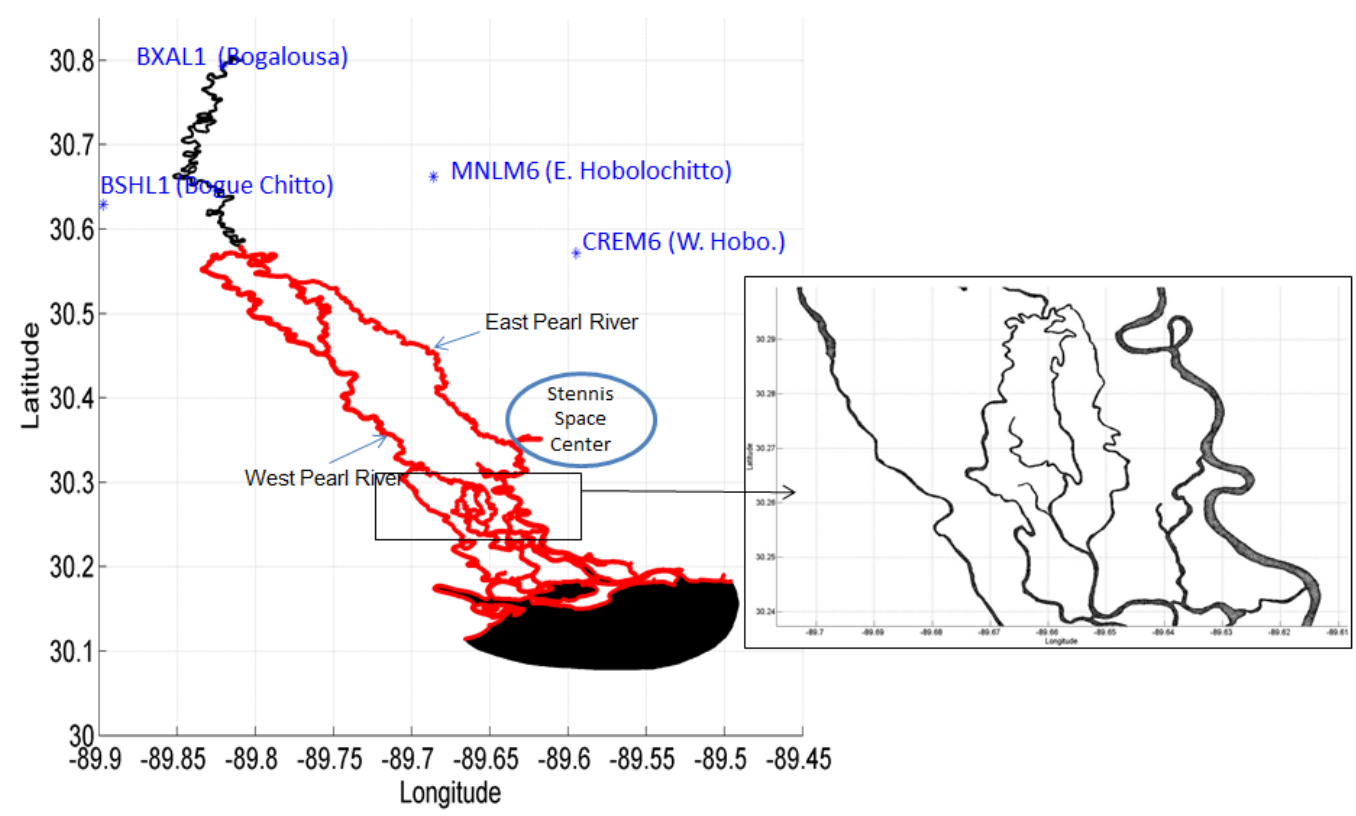

Figure 3 - Pearl River channel mesh (black) with the Bogalousa station (BXAL1) applied as upstream discharge forcing, a truncated version of the channel mesh moving the northernmost boundary just north of the East/West Pearl River split (gray), inset showing the high resolution mesh detail of the West, Mid-, Middle-, and East (left to right) channels in the Pearl River.

\section{RESULTS AND DISCUSSION}

Model simulations for the presented analyses extend for 14 days with the first 4 days used to gradually ramp up the external tidal and riverine forcing. Initial simulation sets applied constant streamflow at the open boundary for representative high, average and low flow conditions for the Pearl River (40,000, 10,000 and 3,000 cfs ). At low flow conditions, simulated water levels and currents appeared reasonable while water levels and currents predicted in river channels started to rise to uncharacteristically high values for the average flow case. Extremely high water levels and unrealistically high currents were predicted for high flow conditions.

\section{Sensitivity Analyses}

A series of sensitivity analyses was conducted to understand the sources of error in high discharge scenarios. The sensitivity analyses included considerations of friction coefficient, water depth and channel slope. The sensitivity to friction coefficient was evident especially for currents but all modeled results were realistic within a $C_{f}$ range from 0.0001 to 0.020 as shown in Figure 4 for downstream sections in West Pearl and Middle Pearl. Results in East Pearl are not shown because the differences for velocities and water levels were smaller in the downstream East Pearl section selected for comparison. Water levels in lower reaches of the basin were insensitive to different friction coefficients within that range while currents exhibited higher sensitivity. It may be seen that the velocities for friction coefficients higher than 0.010 were much smaller than those with friction coefficient values lower than 0.003. Considering the friction coefficients used for earlier studies in the region, further model simulations were conducted using a friction coefficient value of 0.001 . 

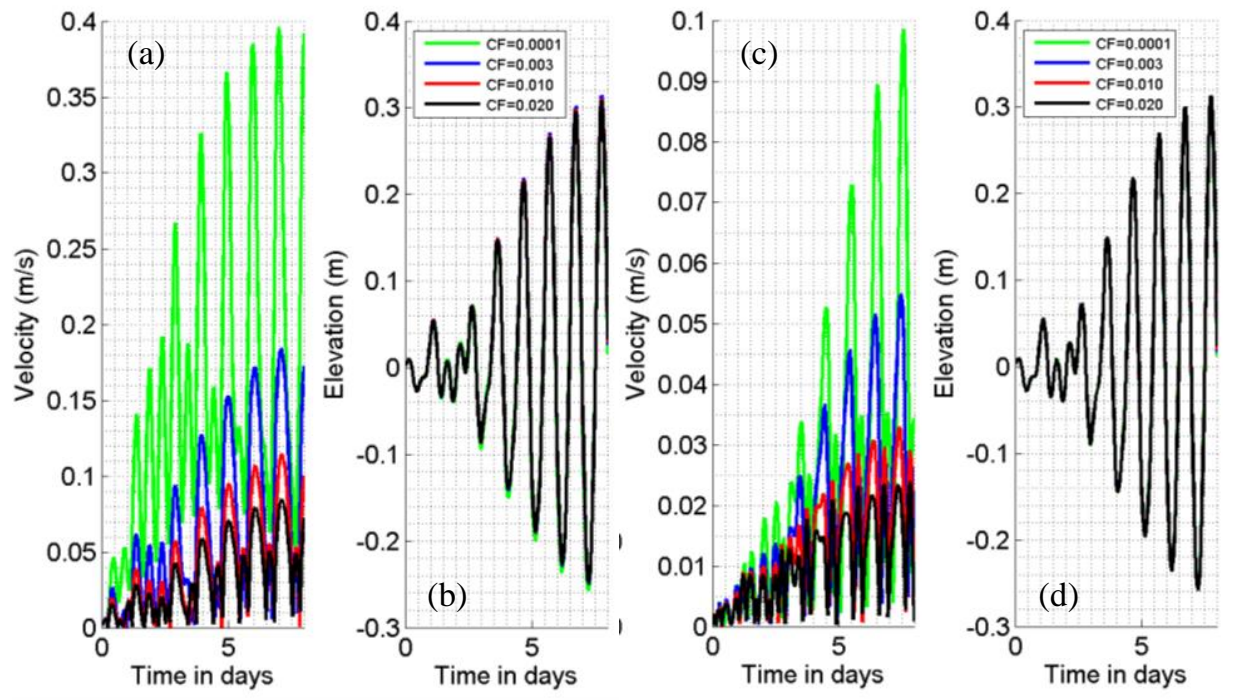

Figure 4 - Modeled current and water level results using different friction coefficients for (a) Velocity(current) and (b) Elevation(water level) on the West Pearl; (c) Velocity and (d) Elevation on the Middle Pearl.

After the river channel depths were determined as described in the previous section, a realistic channel bathymetry was constructed by tilting the mesh from the coastline to upstream locations using a representative constant slope for the entire domain. A constant and representative channel slope of 3.3832E-04 was calculated and used for all the channels within the Pearl River channel model. In reality, certain parts of the river have steeper slopes while other sections have milder slopes based on the real topography. In fact, the slopes at the downstream reaches of the basin were found to be milder than the constant slope used. Figure 5 shows the variation of the channel slopes calculated for different segments of the river from upstream boundary to the coastline based on the topography values provided in the SL16 mesh. It was found that the upstream segments (segments 1,2,3,10,11) has the steepest slope while most of the West Pearl (segments 5 thru 9) and the downstream section of the East Pearl (segment 14) has milder slopes while mid-East Pearl river (segment 12) has the initial slope used for tilting the mesh for a more representative bathymetry.

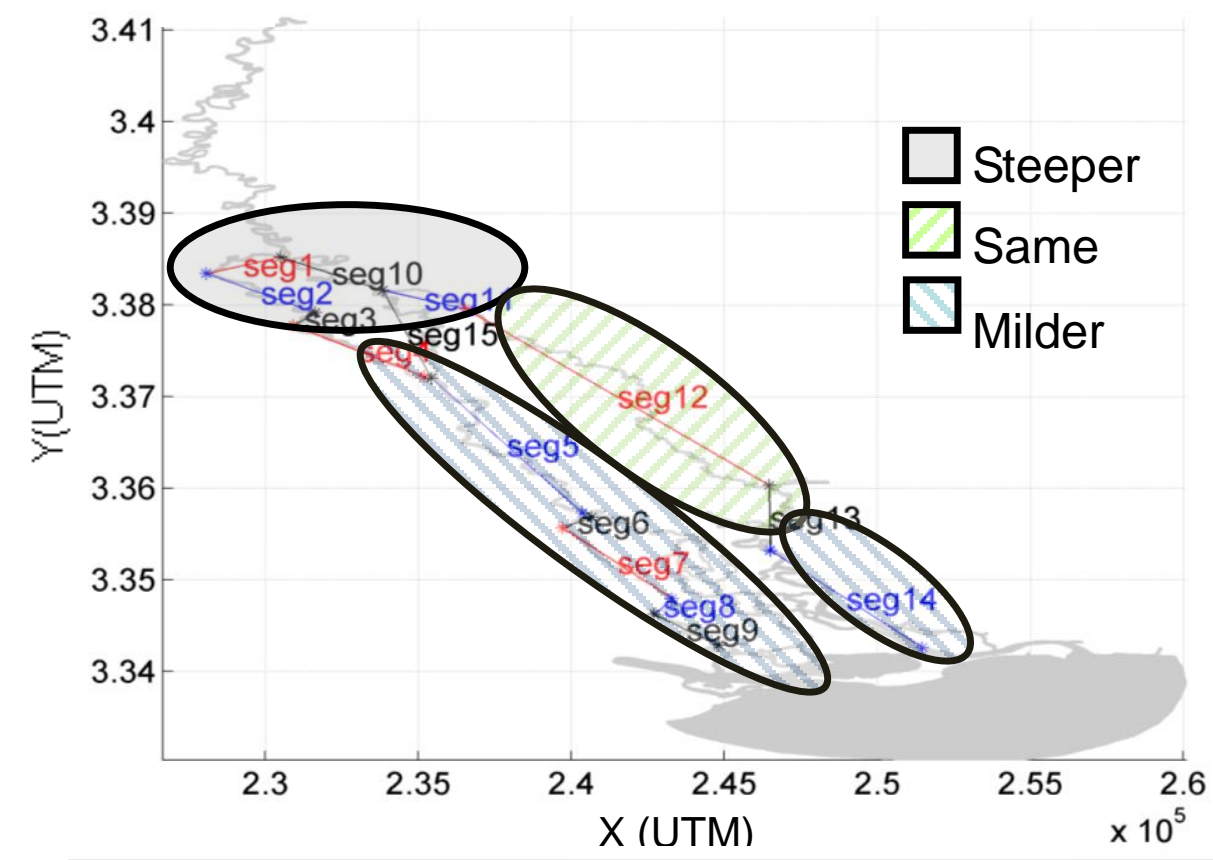

Figure 5 - The variation of topographic slope in West Pearl and East Pearl river segments compared to the constant representative slope used for the entire Pearl river channel model. 
Figure 6 shows the computed velocity and elevation variations for the high flow scenario subject to a constant friction coefficient, $C_{f}=0.001$, at two different constant channel depths, $10 \mathrm{~m}$ and $15 \mathrm{~m}$. The results are shown for downstream locations on the Pearl River with a location on the West Pearl at $30.3 \mathrm{~N}$ and on the East Pearl farther downstream at 30.2N. From Figure 6, the water level and velocity means increase during the first 4 days of the simulation when the forcing is ramped up. After Day 4, the water levels and velocities vacillate around this mean value due to tidal fluctuations for water depths equal $15 \mathrm{~m}$. The mean velocity of $0.35 \mathrm{~m} / \mathrm{s}$ on the West Pearl is higher than that on the East Pearl with values of $0.1 \mathrm{~m} / \mathrm{s}$, while the ranges of velocity and water level are similar in both channels. When water depths are $10 \mathrm{~m}$, the velocity and water levels in the West Pearl do not reach a steady state after the ramp period. Rather they continue to increase even at Day 8 of the simulation time period. For this case, the velocity range on the East Pearl is higher $(0.2 \mathrm{~m} / \mathrm{s})$ than that of the West Pearl. The water level on East Pearl was not affected by the bathymetry change at this downstream location. These results indicate that there is a critical depth between $10 \mathrm{~m}$ and $15 \mathrm{~m}$ at which model stability is disturbed.
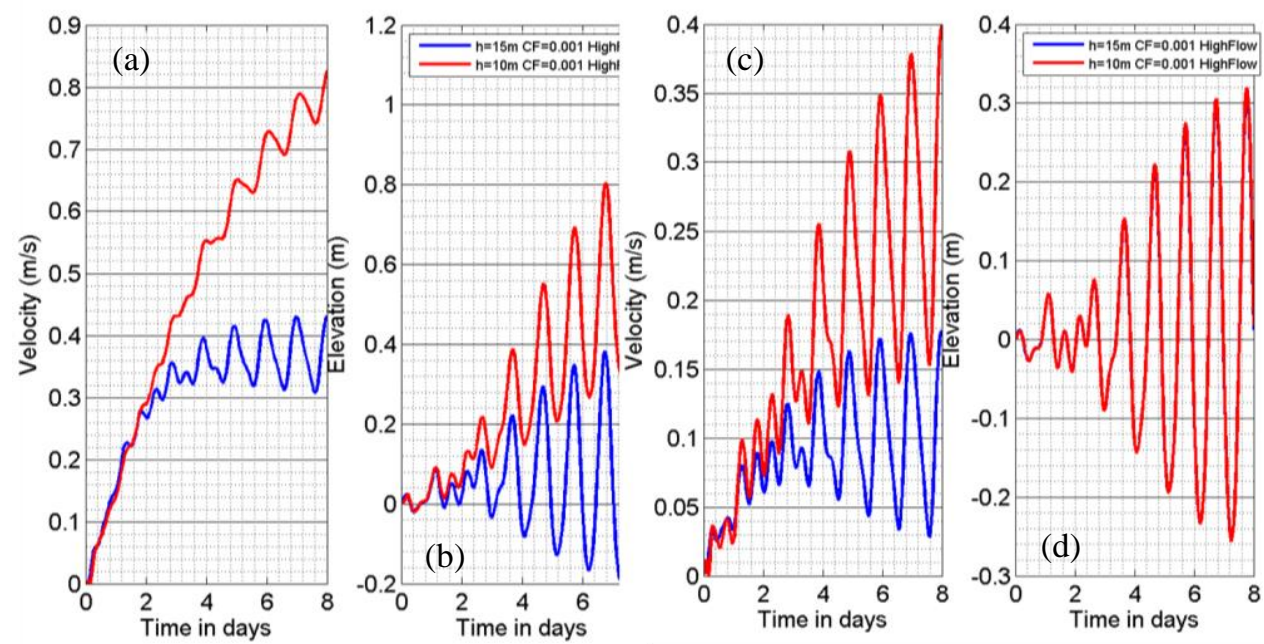

Figure 6 - Modeled currents and water levels using different constant channel water depths (15m vs. 10m) for (a) Velocity and (b) Elevation on the West Pearl; (c) Velocity and (d) Elevation on the East Pearl.
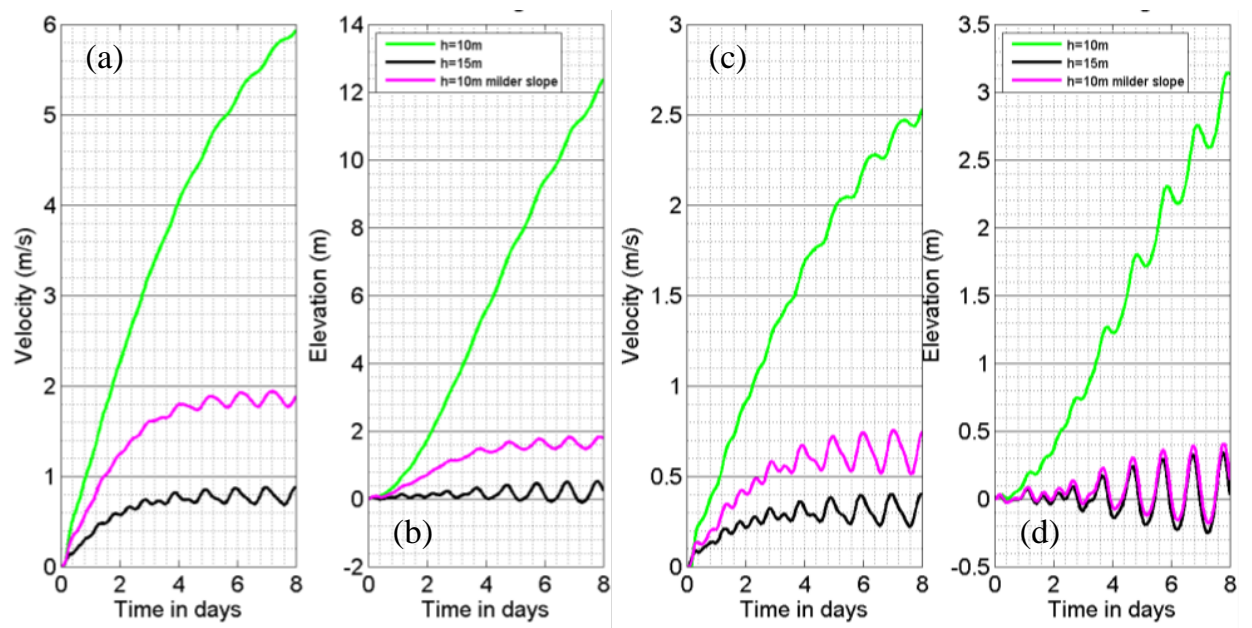

Figure 7 - Modeled currents and water levels using different constant channel water depths (15m vs. 10m) and different slopes (original slope vs. milder slope) for (a) Velocity and (b) Elevation at the West Pearl; (c) Velocity and (d) Elevation at the East Pearl.

Figure 7 shows the impact of channel depth and channel slope on model predictions at $30.45 \mathrm{~N}$ on both the West Pearl and East Pearl river main branches. Once again velocities and elevations (water levels) within both main branches of the Pearl River reach a steady mean with fluctuations around that mean for constant $15 \mathrm{~m}$ water depth (black lines). In contrast, water level and velocities at the midlatitude locations on both the West and East Pearl continuously increase for the first 8 days of the 
simulation when the water depth is set at a constant $10 \mathrm{~m}$ (green lines). When a milder constant channel slope is applied to the constant $10 \mathrm{~m}$ depth case, the water levels and velocities stabilize. This is likely because using milder slopes in lower reaches of the basin resulted in a decrease in velocities which did not exceed the capacity of the river channels. These results show the importance of accurate channel bathymetry and topography for realistic predictions of water level and velocity in river channels. Results indicate that the largest sensitivity of water levels and currents in the West and East Pearl river is to channel depth with lower sensitivity to channel slope. Both depth and slope factors in the river capacity which, in turn, is directly related to the ability of the river to contain upstream discharges within the river channels.

\section{Capacity Analyses}

We have conducted an analysis on the capacity of the channels to better understand the development of instabilities during average and high flow conditions. This analysis has been conducted on both West Pearl and East Pearl river channels since increased velocities were observed on both main stems of the Pearl River. The maximum channel discharge capacity has been calculated based on Manning's equation:

$$
Q=\frac{A}{n} R^{2 / 3} S^{1 / 2}
$$

in which a constant roughness coefficient of 0.22 and a representative constant average slope from upstream boundary to the coastline was used.

The channel area was computed by integrating the synthetic bathymetry profile over the channel width for all channel boundary nodes. Figure 8(a) shows the discharge capacity of the Pearl River channels from the upstream boundary towards the coastline, Figure 8(b) and 8(c) show the variation of West Pearl and East Pearl River discharge capacity vs. latitude, respectively. The West Pearl capacity is higher than the average flow discharge of 10,000 cfs (Avg. line in Figure 8) while the East Pearl capacity is lower at the same latitudes for the upstream reaches of the river. On the other hand, the East Pearl is wider and can carry more river flux at the downstream reaches, south of $30.3 \mathrm{~N}$. Multiple choke points with discharge capacity of the river less than the average flow are observed for average flow conditions for both main river channels. In fact, the river discharge capacity is less than the high flow conditions in modeled stretches of both the West Pearl and East Pearl rivers. Such choke points are indicative that overbank flows must occur at these locations, sending water from the channels into the floodplain under both high upstream discharge and at times low upstream discharge conditions.

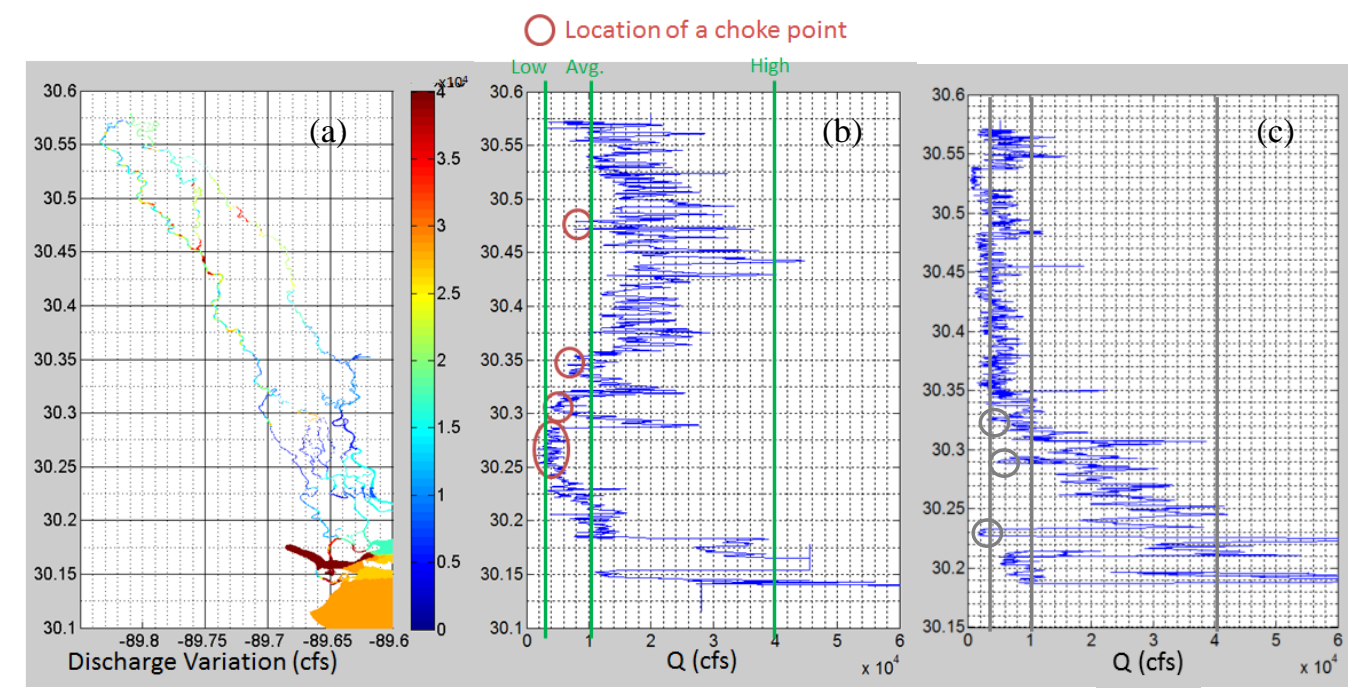

Figure 8 - (a) Discharge capacity variation in the Pearl River channel model, (b) Discharge capacity of the West Pearl River compared to low, average and high upstream flux conditions, and (c) Discharge capacity of the East Pearl River compared to low, average and high upstream flux conditions. 


\section{Floodplain Model Development}

The simulations and analysis with the river channel model has shown a need to expand the model to cover the floodplain of the Lower Pearl River Basin so that high flux which leads to overbank flows and flooding scenarios can be successfully simulated. The high resolution river channel model is expanded by incorporating it into a larger domain ADCIRC mesh of US East Coast (SL16 mesh) used in prior studies for hurricane modeling (Dietrich et al., 2011). A multistep manual mesh development process was followed to accomplish this task using the meshing tool, MeshGUI (Blain et al., 2008). First, the area covered by the river channel model was cut from the large domain model as shown in Figure 9(a). Then, the channel model was inserted into the voided area as shown in Figure 9(b). The resolution at the channel banks are higher than the surrounding floodplain resolution, therefore a gap was left between the channel mesh and the surrounding floodplain. This gap between the channel mesh river banks and the boundary of the larger domain mesh surrounding the channels was carefully meshed to allow for a smooth transition in element size. A segmented approach was followed due to the meandering nature of the river channels. The voided gaps were carefully meshed segment by segment from the upstream boundary of the mesh to coastline downstream (Figure 9(c)). The final product results in a single continuous floodplain mesh for the Lower Pearl River basin that contains the highly resolved Pearl River channels as shown in Figure 9(d).
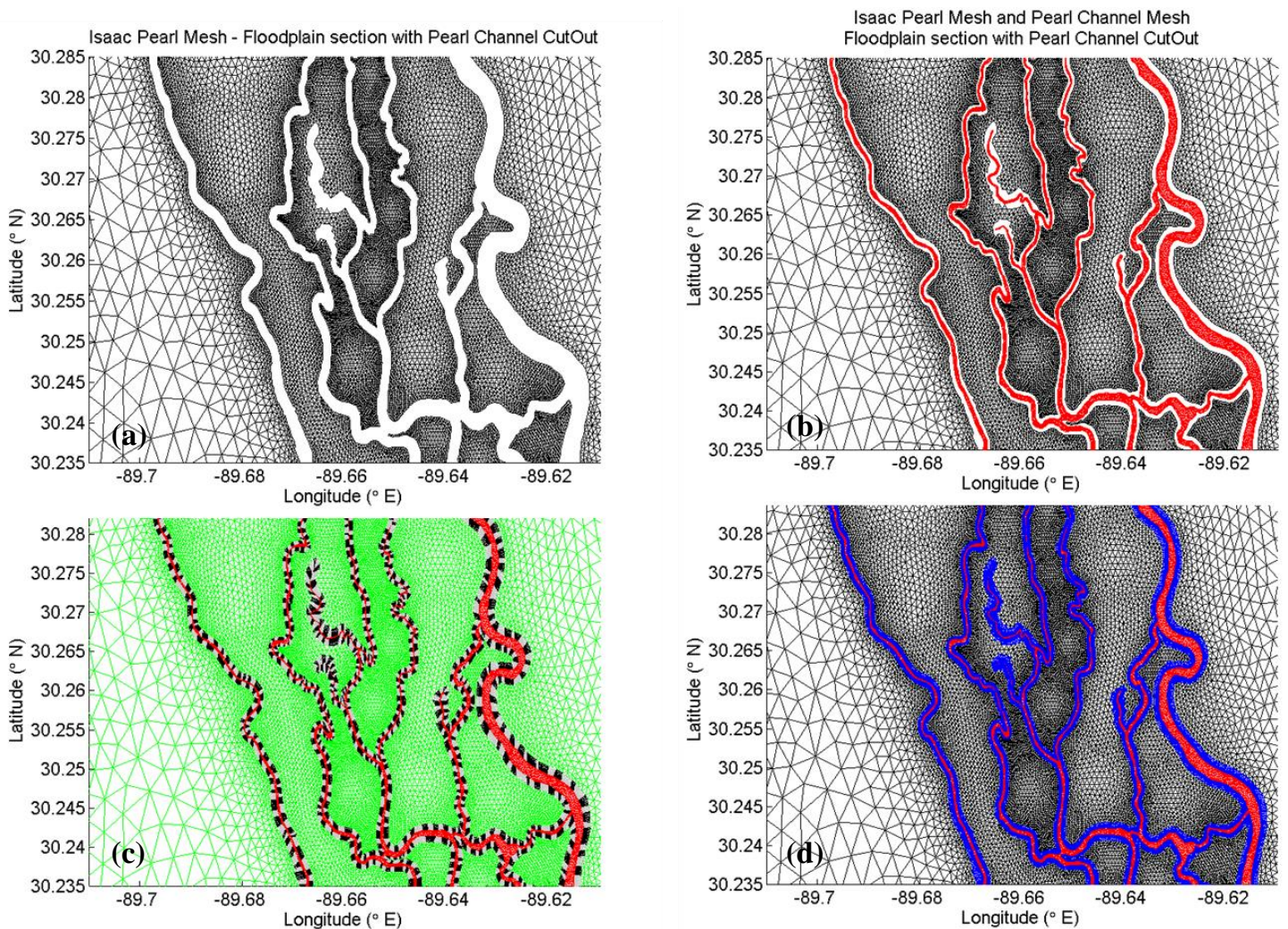

Figure 9 - Stages of mesh development for an extension of a river channel model to the floodplain (a) Pearl River channel mesh area cut from a larger domain US East Coast mesh, (b) Pearl River channel mesh inserted into the cut void area around Pearl River, (c) The segments (grey and black alternating) used to mesh the transition area between river channel mesh bank nodes and the surrounding US East Coast mesh boundary nodes (d) Pearl channel mesh with immediate floodplain elements (bold) meshed around the channels and the original floodplain elements of East Coast US mesh.

The final floodplain model configuration has 421,667 nodes and 842,602 elements maintaining the $\mathrm{O}(1 \mathrm{~m})$ high resolution while providing the floodplain for model wetting and drying to simulate overbank flows and flooding (Figure 10). The final mesh extends south to a boundary in Lake Borgne to the eastern end of Mississippi Sound in the northern Gulf of Mexico where tidal forcing from a validated a tidal database (Lefevre et al., 2002) is applied. Figure 10(b) and 10(c) compare the mesh resolution of the larger domain US East Coast model (SL16) around the West Pearl river channels with the resolution of the floodplain model developed for this study. 


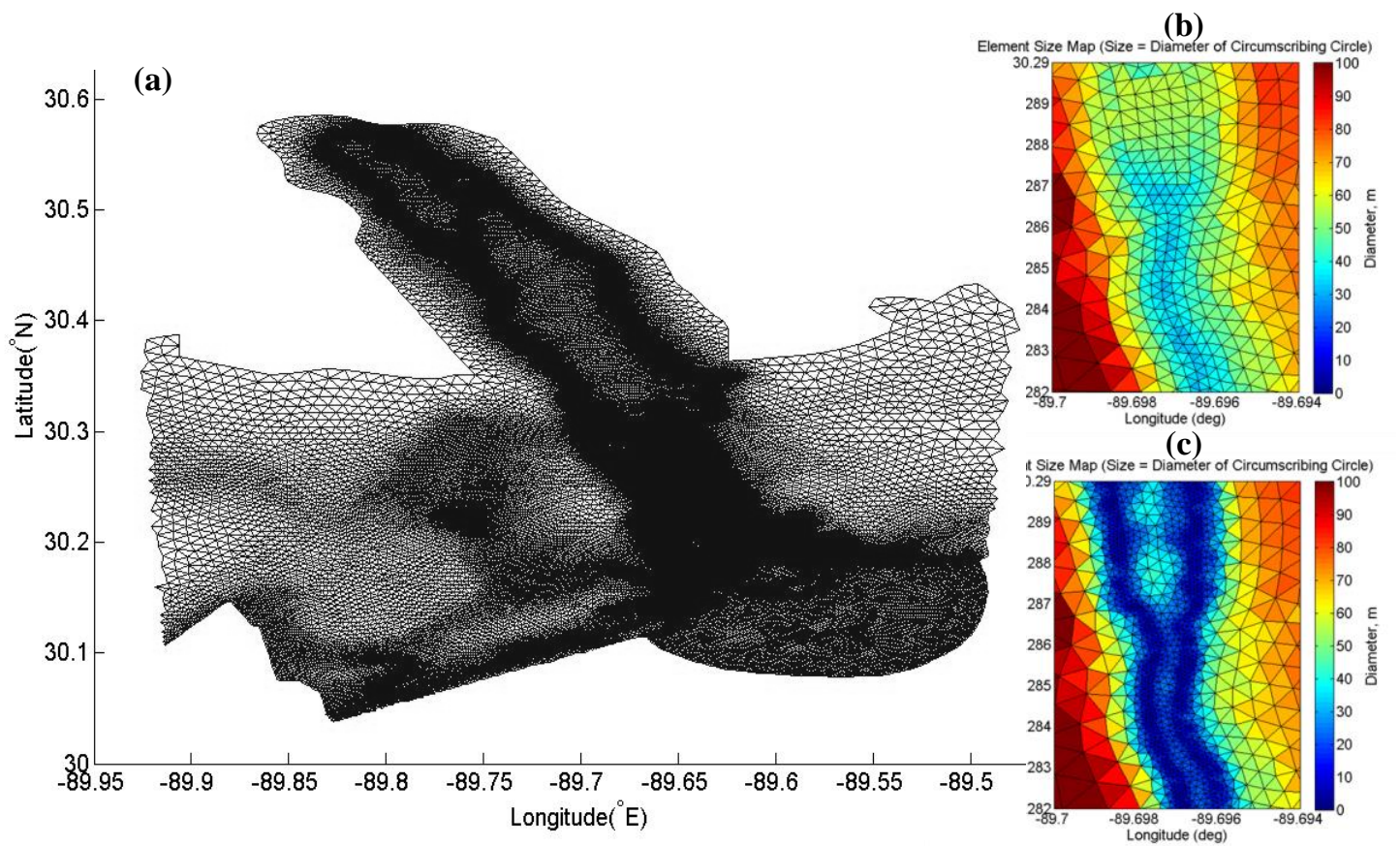

Figure 10 - (a) Pearl River floodplain mesh in the Lower Pearl River Basin, (b) Mesh resolution of the larger domain US East Coast model mesh around the Pearl River at the inset, (c) Mesh resolution of the floodplain model around the Pearl River at the inset.

Model bathymetry and slope are realistically captured as shown in Figure 11, based on the topographic values of the SL16 mesh used for Hurricane Gustav (2008) simulations in the area (Dietrich et al., 2011). The river forcing was applied at specified flux boundaries where upstream discharge values from the main tributaries of the basin are provided by forecast hydrographs. At this time only discharge from the Bogalousa, LA station was active.

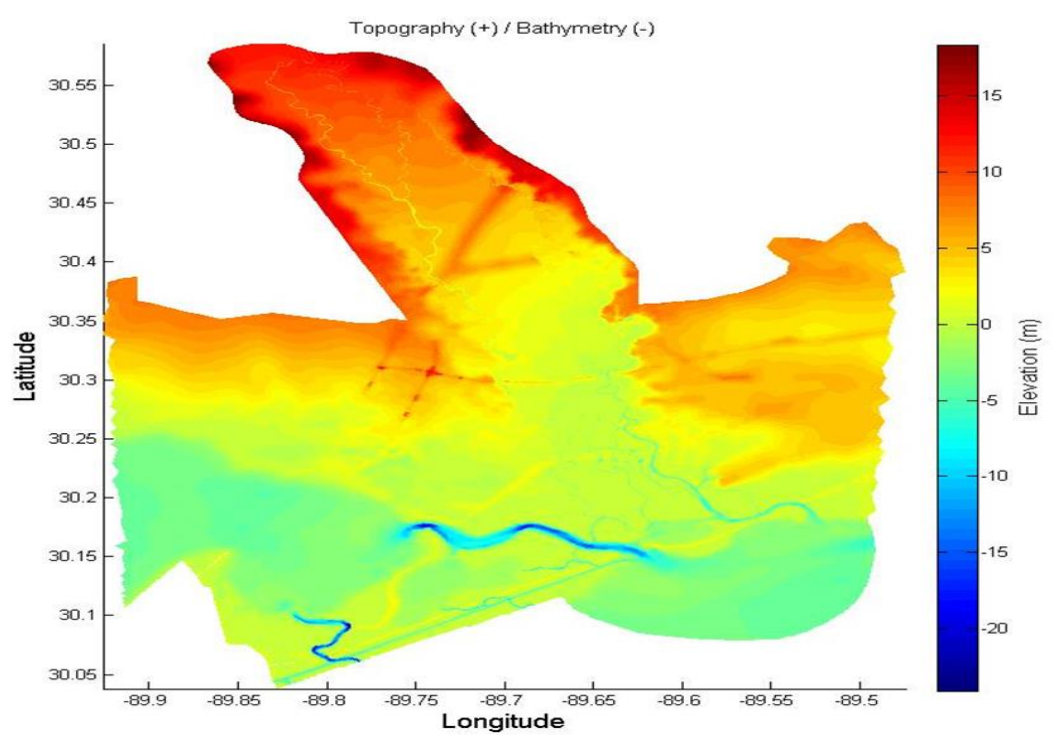

Figure 11 - Pearl River floodplain model bathymetry for the Lower Pearl River Basin.

\section{Floodplain Model Testing}

Water levels from an initial test of the new floodplain model for a low-flow scenario are shown in Figure 12. Tidal constituents were applied along the arc-shaped open boundary in the southeastern corner of the domain forcing tidal fluctuations into the domain. The tides will travel via the Rigolets channel, connecting Lake Ponchartrain and Lake Borgne. Tidal levels may be seen traveling into Lake Ponchartrain via the Rigolets in Figure 12. The tides will also travel upstream into all of the Pearl River 
channels. This preliminary result indicates river flow coming downstream while remaining within the river channels due to flux initiated at the upstream boundary. No flooding from the upstream fiver flux is observed as expected. An area along the northeastern shore of Lake Ponchartrain that was initially dry, wetted during this simulation demonstrating the functionality of the wetting/drying mechanism within the modeling system. This mesh will be finalized to conduct hindcast simulations of Hurricane Isaac as well as other large precipitation/discharge events. Additionally, smaller channels for the Bogue Chitto and Hobolo Chitto creeks will be added and connected to the main Pearl River stems. These creeks will extend to hand-off locations near the NOAA NWS gage locations for these creeks.

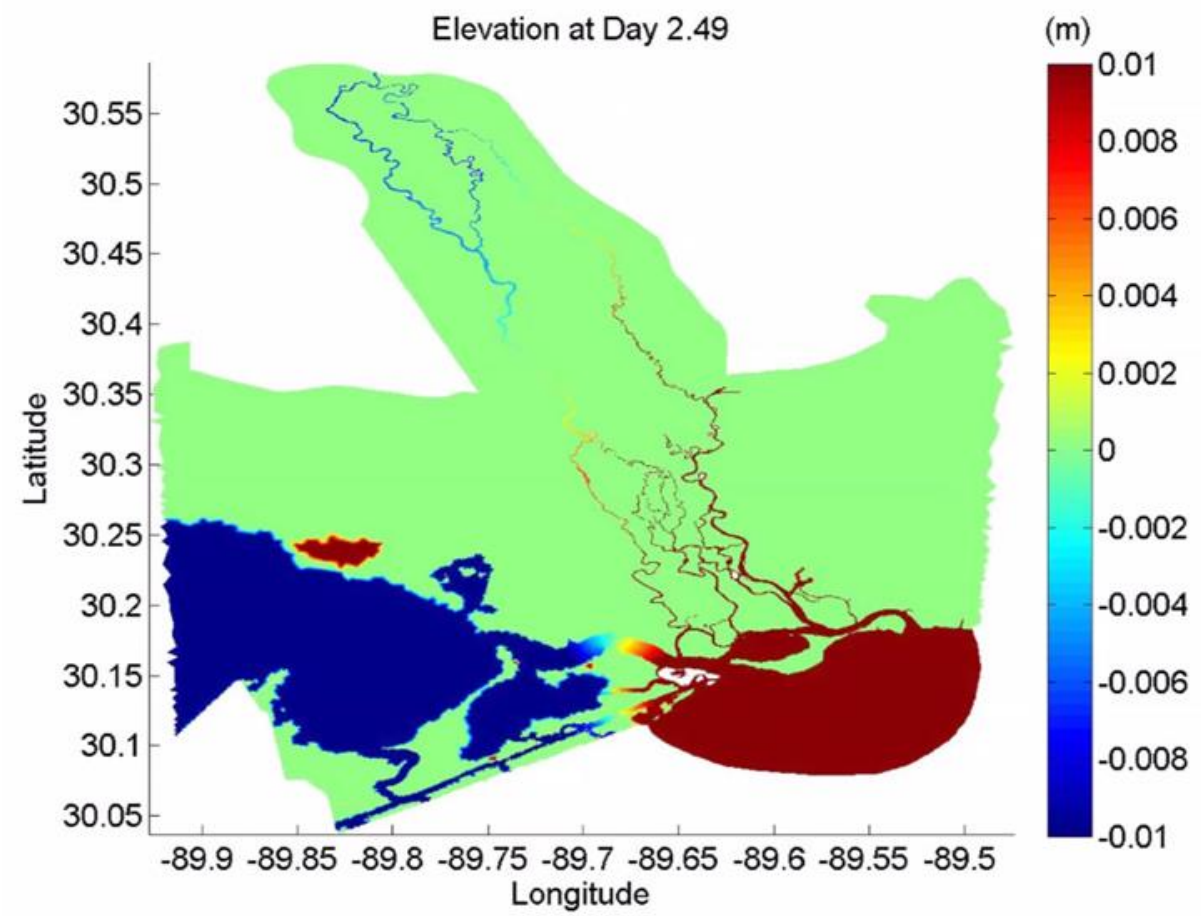

Figure 12 - Preliminary result for water levels predicted by the Lower Pearl River Basin floodplain model.

\section{SUMMARY AND CONCLUSION}

This study has shown the capability of Advanced Circulation Model, ADCIRC, in simulating riverine flow of a complex, braided river system, the Pearl River in the Lower Pearl River Basin. A developed channel mesh resolves the main West Pearl and East Pearl river channels as well as the highly complex mid-, middle- Pearl channels at $\mathrm{O}(\mathrm{m})$ resolution. A series of sensitivity analyses indicated that model stability is assured for low flow and typically maintained for average river flow conditions. Unrealistically elevated water levels and currents occurred during a high river flow case. Channel depth was found to be the most sensitive river parameter when considering depth, bottom friction and slope. An examination of river capacity revealed that at high flow, and at times, average flow conditions the capacity of the river to transmit high flow events was exceeded and that such fluxes would likely result in overbank flow at identified choke points. This exceedance of the river capacity at high flow demonstrated the need for developing a river model that includes the floodplain surrounding the river channels. Subsequently, the details of constructing a floodplain model with high resolution in the channels connected seamlessly to the surrounding floodplain are presented. Preliminary results for low flow conditions using this floodplain mesh of the Lower Pearl River Basin are presented. This floodplain model is currently under final development and testing phases so that Hurricane Isaac hindcast simulations may be conducted to simulate the Pearl River flooding in southeastern Louisiana and Mississippi. The developed model with a realistic representation of the Pearl River will provide an important prediction tool to decision makers for better preparation, protection and mitigation for future flooding events in the study area. 


\section{ACKNOWLEDGMENTS}

This research was accomplished using a grant from St. Tammany Parish, Louisiana, USA. The authors would like to thank Mr. Robert Linzell for his contributions to this work. The authors would also like to honor the late Dr. J. Paul McKay for his efforts initiating this research study.

\section{REFERENCES}

Blain, C.A., R.S. Linzell, A. Weidemann, P. Lyon. 2009. A tool for rapid configuration of a river model. In: Proceedings of Oceans 2009 MTS/IEEE Biloxi Conference, Biloxi, MS.

Blain, C.A., M.K. Cambazoglu, R.S. Linzell, K.M. Dresback, and R.L. Kolar. 2012. The predictability of near-coastal currents using a baroclinic unstructured grid model. Journal of Ocean Dynamics. 62(3), 411-437.

Blain, C.A., R.S. Linzell, J.P. McKay. 2013. Simple methodology for deriving continuous shorelines from imagery: Application to rivers. Journal of Waterway, Port, Coastal and Ocean Engineering, 139(5), 365-382.

Blain, C. A., R. Linzell, T. C. Massey, and B. D. Estrade. 2008. MESHGUI: A mesh generation and editing toolset for the ADCIRC model, NRL Mem. Rep. NRL/MR/7320-2007-9083, Naval Research Laboratory, Stennis Space Center, MS.

Dietrich, J.C., J.J., Westerink, A.B., Kennedy, J.M., Smith, R.E., Jensen, M., Zijlema, L.H., Holthuijsen, C.N., Dawson, R.A., Luettich Jr., M.D., Powell, V.J., Cardone, A.T., Cox, G.W., Stone, H., Pourtaheri, M.E., Hope, S., Tanaka, L.G., Westerink, H.J., Westerink, and Z., Cobell. 2011. Hurricane Gustav (2008) Waves and Storm Surge: Hindcast, Validation and Synoptic Analysis in Southern Louisiana. Monthly Weather Review, 139(8), 2488-2522.

Lefevre, F., F. Lyard, E. Le Provost, J. Schrama. 2002. FES99: A global tide finite element solution assimilating tide gauge and altimetric information. Journal of Atmospheric and Oceanic Technology.

Luettich, R., J. Westerink, N. Scheffner. 1992. ADCIRC: An advanced three-dimensional model for shelves, coasts and estuaries, Report 1: Theory and methodology and ADCIRC-2DDI and ADCIRC-3DL, Tech. Rep. DRP-92-6. Tech. rep., Department of the Army, Washington, DC.

Luettich, R., J. Westerink. 2004. Formulation and numerical implementation of the 2D/3D ADCIRC finite element model version 44.XX.

McKay, J.P., and C.A. Blain. 2010. Toward developing a hydrodynamic flow \& inundation model of the Lower Pearl River. Proceedings OCEANS 2009, MTS/IEEE Biloxi - Marine Technology for Our Future: Global and Local Challenges, Biloxi, MS, October 2009.

McKay, J.P., C.A. Blain. 2013. Development and validation of a hydrodynamic flow model of the Lower Pearl River in Louisiana and Mississippi, unpublished report at the Naval Research Laboratory, Stennis Space Center, MS.

McKay J.P., C.A. Blain. 2014. An automated approach to extracting river bank locations from aerial imagery using image texture, River Research and Applications, 30(8),1048-55.

Moorhead, R. 2014. Personal communication. Related online article can be found at: http://www.msstate.edu/newsroom/article/2014/12/mississippi-states-uas-expertise-display/

NASA. 2001. NASA Stennis Space Center, Environmental resource document, inventory summary for John C. Stennis Space Center: Chapter 3. Water Resources, Stennis Space Center, MS, April 2001.

National Mapping Program. 1996. Standards for digital orthophotos. Tech. rep., US Geological Survey.

Russ, J. 2002. Image Processing Handbook, $4^{\text {th }}$ Ed. CRC Press.

Tanaka, H. 2006. Monitoring of short-term morphology change at a river mouth. In: Proceedings of the Vietnam-Japan Estuary Workshop. 